\title{
Creative Thinking in Tourette's Syndrome: An Uncharted Topic
}

\author{
Laura Colautti $^{1 *}$, Sara Magenes ${ }^{1,2}$, Sabrina Rago ${ }^{1}$, Carlotta Zanaboni Dina ${ }^{1}$, Alice Cancer ${ }^{1}$ \\ and Alessandro Antonietti ${ }^{1}$
}

${ }^{1}$ Department of Psychology, Università Cattolica del Sacro Cuore, Milan, Italy, ${ }^{2}$ Fraternità e Amicizia Società Cooperativa

Sociale ONLUS, Milan, Italy

Keywords: creative thinking, flexibility, tourette's syndrome, assessment, dopamine

\section{INTRODUCTION}

This opinion article discusses the literature about creativity in patients with Tourette Syndrome (TS) and provides some suggestions about how this topic might be further exploited. TS is a neurodevelopmental disorder, with an onset occurring before the age of 18 (Robertson, 2011). The main symptom is the presence of tics, of which one or multiple sound tics and multiple motor tics (American Psychiatric Association, 2013). TS is associated with other potential impairments, such as cognitive anomalies, physical pain, impairment in daily activities, emotional and behavioral problems (Cavanna et al., 2013; Morand-Beaulieu et al., 2017).

Despite these problems, high levels of creativity have been reported in TS patients. Examples of eminent individuals, e.g., W. A. Mozart (Ashoori and Jankovic, 2007), allegedly affected by TS, have been described (Szejko et al., 2019). On these premises, researchers studied more recent cases of TS patients showing creative aptitudes and measured the average levels of creative skills in samples of TS patients, to speculate about the reasons why these patients excel in creativity.

\section{CREATIVITY AND ITS NEURAL CORRELATES}

Creativity has been described as a highly functional way of thinking (Dietrich, 2004) leading people to break the usual and automatic responses and to develop alternative behaviors (Heilman, 2016). A "bizarre" idea is not necessarily a creative one; Creative thinking is related to the production of ideas which are both new and appropriate (Runco and Charles, 1993). Creativity includes thinking "beyond borders" enabling people to move away from stereotyped mental schemas (Shamay-Tsoory et al., 2011).

Three neural systems underlie creative thinking (Beaty et al., 2018; Goldberg, 2018): (a) the default network (DN), linked to the generation of ideas through the involvement of mnestic retrieval and mental simulation; (b) the salience network (SN), crucial for the identification of relevant information; (c) the executive control network (ECN), essential for the elaboration, evaluation, and revision of information to maintain a goal-oriented process. Specific neural sites underlie each of these networks: DN involves the ventromedial prefrontal cortex (vmPFC), the orbitofrontal cortex (OFC), the posterior parietal cortex (PPC), and the precuneus. SN includes the insular regions and the anterior cingulate cortex (ACC), whereas ECN encompasses the dorsolateral prefrontal cortex (dlPFC) (Colombo et al., 2015), the ventrolateral prefrontal cortex (vlPFC), and the PPC (Beaty et al., 2018; Goldberg, 2018). The prefrontal cortex (PFC) covers a key role, devoted to the integration of the information, the control of voluntary behaviors, and the inhibition of inadequate responses (Volle et al., 2013; de Souza et al., 2014).

Neurotransmitters are important for creativity as well, in particular dopamine (Lhommée et al., 2014; Khalil et al., 2019). An increase in creative thinking has been reported in Parkinson's Disease

doi: 10.3389/fpsyg.2021.649814
(PD) patients after the intake of dopamine drugs (Canesi et al., 2012) and in patients with a 
pathological excess of dopamine, as occurs in schizophrenia (Folley and Park, 2005; Acar et al., 2018). This is in line with studies showing that dopamine is important for reward drives, curiosity (Flaherty, 2011), and mental associations (McNab et al., 2009), which are linked to creativity.

\section{TS AND DOPAMINE}

The effects of dopamine on creativity are little-known, especially in developmental conditions associated with higher dopamine levels, such as TS. TS is indeed characterized by a dopamine dysfunction due to an atypical neurotransmitter distribution, with an over-activation of dopaminergic circuits in basal ganglia (BG) (Klimkeit and Bradshaw, 2006; Szejko et al., 2019).

The majority of TS symptoms are linked to cortico-striatothalamo-cortical circuits (which have an important role in communicating with cortical and subcortical structures), and in particular to the frontostriatal system, including dlPFC, lateral OFC, supplementary motor area, ACC, and associated BG structures (Bradshaw and Sheppard, 2000), namely, in brain areas involved in creativity.

In TS, drugs can be prescribed to block the activity of the dopamine receptors, reducing the symptoms during daily activities. Medications can have side effects and, when antidopaminergics are included, a reduction of creativity may occur (Thenganatt and Jankovic, 2016; Porta et al., 2017).

\section{TS AND CREATIVE THINKING}

Considering the neural structures involved in TS and the fact that most of them correspond to those involved in creative processes, it has been postulated that the excess of dopamine characterizing TS can enhance creative thinking (Espert et al., 2017). Sacks (quoted in Bradshaw and Sheppard, 2000, p. 307) described TS as "a continuum with two ends: One (stereotypic) extreme involves simple motor tics and vocalizations, iterations, and perseverations, which are largely a nuisance and an irrelevance; The other extreme involves elaborations, playful mimicry, extravagant impudent inventiveness, audacious dramatizations, surreal associations, uninhibited inventiveness, incontinent reactivity". The second extreme includes a set of manifestations which are associated to creativity.

Single-case studies showed that TS patients have a strong predisposition to, or excel in activities and jobs requiring creativity (Barber, 2016; Porta et al., 2017; Szejko et al., 2019; Zanaboni Dina and Porta, 2019). A recent case is worth mentioning: the soccer player Tim Howard ${ }^{1}$, who developed a personal style of goalkeeping by combining the use of all limbs.

Patients who show higher levels of creativity tend to use TS symptoms to their advantage, obtaining "benefits" from them (Zanaboni Dina and Porta, 2019). Sacks (1992) reported cases of patients who benefited from their symptoms. A TS patient wrote great and brilliant novels, driven by his Tourettic expressive force. A jazz musician was famous for his dynamic improvisations caused by his tics: They were not considered to be mistakes

${ }^{1} \mathrm{https}: / /$ www.youtube.com/watch?v=9IaSOktjtv4 during his performance, but they became its core feature. After a pharmacological treatment, the musician felt calmer and more mindful, but he lost inspiration in improvisation.

Furthermore, regardless of the presence and the type of medication, tics appear to be less intense when TS patients are engaged in creative and artistic performances, such as dancing, painting, or listening to music, but not in other activities (e.g., doing homework, playing videogames) (Caurín et al., 2014).

\section{EMPIRICAL STUDIES}

A search was conducted in Pubmed, PsycINFO, Scopus, and the Cochrane Library databases using the search terms "Tourette's Syndrome" in combination with "creative thinking" and "creativity". Only two studies investigating creativity in TS using specific tools for the assessment of patients (Wei, 2011; Zanaboni Dina et al., 2017) were found (see Table 1).

In the first study (Wei, 2011) a group of Taiwanese children affected by TS has been matched to a group of typically developing ones. Consistently with the aim of this article, only results related to creative thinking were considered. To assess creativity the Author employed a divergent thinking test composed of 12 drawings that the participants had to complete. TS children got a significant lower score in elaboration, whereas they scored higher in originality, but the difference between the two groups was not statistically significant.

In the second study (Zanaboni Dina et al., 2017), adult TS patients were compared to adults with $\mathrm{PD}$. The two groups were different in age (the TS group was younger than the PD one), in pathology (TS is a neurodevelopmental disorder, PD is a neurodegenerative one), and opposite in therapy (TS therapy usually reduces dopamine levels, PD drugs enhance them). The assessment was based on verbal tasks requiring divergent thinking to process the stimuli. The TS group was more creative in all parameters, even though statistically significant differences emerged only in total creative thinking, inventing phrases, and producing hypotheses scores.

The two studies cannot be compared for two main differences. First, the type of creative task used (figural vs. verbal). Second, the samples' characteristics (study 1: TS children vs. healthy controls; study 2: TS adults vs. PD adults) and medications (study 1: none; study 2: patients undergone different medical therapies or no medications) are dissimilar.

\section{DISCUSSION}

It has been reported that TS patients may exhibit creative attitudes in artistic domains and professional fields in which creativity is required (Sacks, 1992; Porta et al., 2017; Szejko et al., 2019; Zanaboni Dina and Porta, 2019). Studies showed higher scores by TS patients in some dimensions assessed by creativity tests, although differences with matched groups were not always statistically significant (Wei, 2011; Zanaboni Dina et al., 2017). Hence, even if there is no conclusive evidence of an enhanced creativity in TS, data suggest that a creative potential is latent in such a condition. 
TABLE 1 | Included studies.

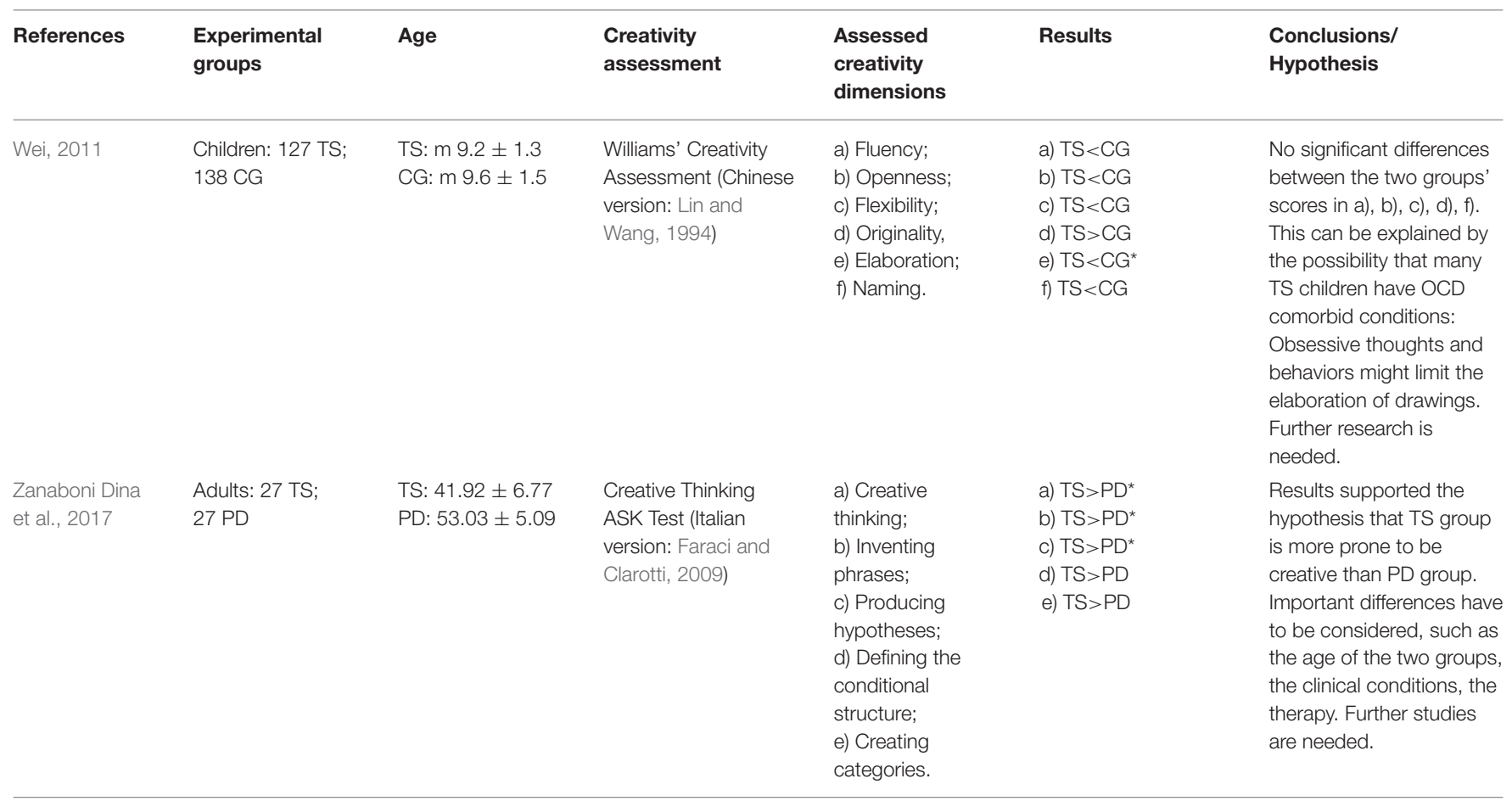

TS, Tourette's Syndrome; CG, Control Group; PD, Parkinson's Disease. ${ }^{*} p<0.05$.

The creative profile of TS patients can be supported by a possible neurobiological basis. In fact, patterns of enhanced creativity in TS patients can be explained referencing to alterations in dopamine mechanisms. Creative thinking and behavior (i.e., mental associations and curiosity) are fostered by dopaminergic neurotransmission (Lhommée et al., 2014; Boot et al., 2017; Khalil et al., 2019). The hypersensitivity to postsynaptic dopamine receptors (Singer and Walkup, 1991), which characterizes TS, may contribute to the presence of high levels of creativity.

The creative potential in TS patients can be connected to studies using neuroimaging techniques in resting state. TS patients show larger volumes in dorsal PFC and parieto-occipital regions than healthy controls (Peterson et al., 2001), as well as abnormalities in the cortico-striato-thalamo-cortical circuits (Neuner et al., 2010) and altered connectivity patterns between PFC, frontal cortex, midcingulate cortex, precuneus, and inferior parietal gyrus (Church et al., 2009). These areas partially overlap those related to creative thinking, especially PFC, which has a pivotal role in the main mental operations required by creativity.

It has been claimed that creativity plays a crucial role when individuals are challenged, for instance because of neurodevelopmental disorders (Cancer et al., 2016), cognitive impairments (Fusi et al., 2020), brain damages (Colautti et al., 2018), and mental decline associated to aging (Colombo et al., 2018). Original ways to overcome the problems associated to these conditions, when the usual strategies fail, can be found. Hence, creativity can be a resource for TS patients to develop alternative and functional behaviors, helping them cope with their symptoms and promote their well-being.

In addition, the awareness that TS is not associated only to deficits but also to enhanced abilities, such as creativity, can lead patients to develop a more positive representation of themselves. Thus, studying the presence of creativity in TS appears of importance to better understand patients' strengths, integrating into their treatment pathways effective solutions to improve their well-being.

\section{Future Directions}

Further research could investigate creativity (i) across the lifespan; (ii) taking into account social context, parental care, school education, and interactions with peers; (iii) applying standardized approaches. In particular, the use of questionnaires and checklists (i.e., Creative Achievement Questionnaire-CAQ; Carson et al., 2005, or Creative Activity and Accomplishment Checklist-CAAC; Paek et al., 2016) is suggested. Furthermore, studies should consider both the presence of comorbidities, the assumption of drugs, matched controls to make comparisons, and the use of neuroimaging and psychophysiological techniques to investigate the brain circuitry. Genetic bases of TS might be associated to creativity levels as well. Tools which allow a systematic measure of creativity, rather than narrative reports, can provide a more reliable framework. Administering the most used tests to assess creativity (i.e., Torrance Test of Creative Thinking-TTCT; Torrance, 1998) and/or specific mechanisms (i.e., remote associations, Bowden and Jung-Beeman, 2003, 
or insight, Iannello et al., 2020) is preferable. This should make the comparison of TS findings with those on other pathologies possible. Furthermore, since creativity involves not only divergent thinking but also convergent thinking, further studies should consider both processes. Also, the assessment of personality traits may show if specific personality traits in TS patients are associated with creativity (Abdullah et al., 2016).

Finally, the application of training programs to improve creativity could be addressed to TS patients (i.e., Zanaboni Dina et al., 2020), revealing functional capabilities that would

\section{REFERENCES}

Abdullah, I., Omar, R., and Panatik, S. A. (2016). A literature review on personality, creativity and innovative behavior. Int. Rev. Management Marketing 6, 177-182.

Acar, S., Chen, X., and Cayirdag, N. (2018). Schizophrenia and creativity: a metaanalytic review. Schizophr. Res. 195, 23-31. doi: 10.1016/j.schres.2017.08.036

American Psychiatric Association (2013). Diagnostic and Statistic Manual of Mental Disorders, 5th ed. Arlington, VA: American Psychiatric Publishing. doi: 10.1176/appi.books.9780890425596

Ashoori, A., and Jankovic, J. (2007). Mozart's movements and behaviour: a case of Tourette's syndrome? J. Neurol. Neurosurg. Psychiatr. 78, 1171-1175. doi: 10.1136/jnnp.2007.114520

Barber, L. (2016). An Unlikely Strength: Tourette Syndrome - The Search for Happiness in 60 Voices. SQ Press.

Beaty, R. E., Kenett, Y. N., Christensen, A. P., Rosenberg, M. D., Benedek, M., Chen, Q., et al. (2018). Robust prediction of individual creative ability from brain functional connectivity. Proc. Natl. Acad. Sci. U.S.A. 115, 1087-1092. doi: 10.1073/pnas.1713532115

Boot, N., Baas, M., van Gaal, S., Cools, R., and De Dreu, C. K. W. (2017). Creative cognition and dopaminergic modulation of fronto-striatal networks: integrative review and research agenda. Neurosci. Biobehav. Rev. 78, 13-23. doi: 10.1016/j.neubiorev.2017.04.007

Bowden, E. M., and Jung-Beeman, M. (2003). Normative data for 144 compound remote associate problems. Behav. Res. Methods Instrum. Comput. 35, 634-639. doi: 10.3758/BF03195543

Bradshaw, J. L., and Sheppard, D. M. (2000). The neurodevelopmental frontostriatal disorders: evolutionary adaptiveness and anomalous lateralization. Brain Lang. 73, 297-320. doi: 10.1006/brln.2000. 2308

Cancer, A., Manzoli, S., and Antonietti, A. (2016). The alleged link between creativity and dyslexia: identifying the specific process in which dyslexic students excel. Cogent Psychol. 3, 1-13. doi: 10.1080/23311908.2016.1190309

Canesi, M., Rusconi, M. L., Isaias, I. U., and Pezzoli, G. (2012). Artistic productivity and creative thinking in Parkinson's disease. Eur. J. Neurol. 19, 468-472. doi: 10.1111/j.1468-1331.2011.03546.x

Carson, S. H., Peterson, J. B., and Higgins, D. M. (2005). Reliability, validity, and factor structure of the creative achievement questionnaire. Creat. Res. J. 17, 37-50. doi: 10.1207/s15326934crj1701_4

Caurín, B., Serrano, M., Fernández-Alvarez, E., Campistol, J., and Pérez-Dueñas, B. (2014). Environmental circumstances influencing tic expression in children. Eur. J. Paediatric Neurol. 18, 157-162. doi: 10.1016/j.ejpn.2013.10.002

Cavanna, A. E., David, K., Bandera, V., Termine, C., Balottin, U., Schrag, A., et al. (2013). Health-related quality of life in Gilles de la Tourette syndrome: a decade of research. Behav. Neurol. 27, 83-93. doi: 10.1155/2013/732038

Church, J. A., Fair, D. A., Dosenbach, N. U., Cohen, A. L., Miezin, F. M., Petersen, S. E., et al. (2009). Control networks in paediatric Tourette syndrome show immature and anomalous patterns of functional connectivity. Brain 132, 225-238. doi: 10.1093/brain/awn223

Colautti, L., Baldissini, D., Colombo, V., Mottura, S., Sacco, M., Sozzi, M., et al. (2018). CREC: the role of serious games in improving flexibility in thinking in neuropsychological rehabilitation. Br. J. Educ. Technol. 49, 717-727. doi: 10.1016/bjet.12629 otherwise remain unexploited, and thus compensating possible decreases in creativity induced by the antidopaminergic drugs.

\section{AUTHOR CONTRIBUTIONS}

LC and SM conceived the ideas presented. LC, SM, and SR wrote the article. SR formatted the article. AC revised the language. $\mathrm{CZ}, \mathrm{AA}$, and $\mathrm{AC}$ critically revised the manuscript. All authors contributed to the article and approved the submitted version.
Colombo, B., Antonietti, A., and Daneau, B. (2018). The relationships between cognitive reserve and creativity. A study on American aging population. Frontiers in Psychology, 9(764), 1-11. doi10.3389/fpsyg.2018.00764 doi: 10.3389/fpsyg.2018.00764

Colombo, B., Bartesaghi, N., Simonelli, L., and Antonietti, A. (2015). The combined effects of neurostimulation and priming on creative thinking: a preliminary tDCS study on dorsolateral prefrontal cortex. Front. Hum. Neurosci. 9:403. doi: 10.3389/fnhum.2015.00403

de Souza, L. C., Guimarães, H. C., Teixeira, A. L., Caramelli, P., Levy, B., Dubois, B., et al. (2014). Frontal lobe neurology and the creative mind. Front. Psychol. 5:761. doi: 10.3389/fpsyg.2014.00761

Dietrich, A. (2004). The cognitive neuroscience of creativity. Psychon. Bull. Rev. 11, 1011-1026. doi: 10.3758/BF03196731

Espert, R., Gadea, M., Alino, M., Oltra-Cucarella, J., et al. (2017). Neuropsychology of Tourette's disorder: cognition, neuroimaging and creativity. Rev. Neurol. 64, S65-S72. doi: 10.33588/rn.64S01.2017015

Faraci, P., and Clarotti, S. (2009). ASK-Test di Pensiero Inferenziale e Creativo. Firenze: Giunti O.S. Organizzazioni Speciali.

Flaherty, A. W. (2011). Brain illness and creativity: mechanisms and treatment risks. Can. J. Psychiatry 56, 132-143. doi: 10.1177/070674371105600303

Folley, B. S., and Park, S. (2005). Verbal creativity and schizotypal personality in relation to prefrontal hemispheric laterality: a behavioral and near-infrared optical imaging study. Schizophr. Res. 80, 271-282. doi: 10.1016/j.schres.2005.06.016

Fusi, G., Ferrari, E., Zanetti, M., Crepaldi, M., Bersanini, C., Paladino, A., et al. (2020). Divergent thinking abilities in mild cognitive impairment: loss or resource? The relationship with cognition, psychological factors and cognitive reserve. Front. Psychol. 11, 1-8. doi: 10.3389/fpsyg.2020.00738

Goldberg, E. (2018). Creativity: The Human Brain in the Age of Innovation. Oxford: Oxford University Press.

Heilman, K. M. (2016). Possible brain mechanisms of creativity. Arch. Clin. Neuropsychol. 31, 285-296. doi: 10.1093/arclin/acw009

Iannello, P., Colombo, B., Germagnoli, S., and Antonietti, A. (2020). "Enhancing intuition in problem solving through problem finding," in Handbook of Intuition as Practice, ed M. Sinclair (Cheltenham, UK; Northampton, MA: Edward Elgar Publishers), 255-269.

Khalil, R., Godde, B., and Karim, A. A. (2019). The link between creativity, cognition, and creative drives and underlying neural mechanisms. Front. Neural Circuits 13:18. doi: 10.3389/fncir.2019.00018

Klimkeit, E. I., and Bradshaw, J. L. (2006). Anomalous lateralisation in neurodevelopmental disorders. Cortex 42, 113-116. doi: 10.1016/S0010-9452(08)70334-4

Lhommée, E., Batir, A., Quesada, J.-L., Ardouin, C., Fraix, V., Seigneuret, E., et al. (2014). Dopamine and the biology of creativity: lessons from Parkinson's disease. Front. Neurol. 5:55. doi: 10.3389/fneur.2014.00055

Lin, S. T., and Wang, M. R. (1994). The Creativity Assessment Packet. Taipei: Psychological Publications.

McNab, F., Varrone, A., Farde, L., Jucaite, A., Bystritsky, P., Forssberg, H., et al. (2009). Changes in cortical dopamine D1 receptor binding associated with cognitive training. Science 323, 800-802. doi: 10.1126/science.1166102

Morand-Beaulieu, S., Leclerc, J. B., Valois, P., Lavoie, M. E., O'Connor, K. P., and Gauthier, B. (2017). A review of the neuropsychological dimensions of Tourette Syndrome. Brain Sci. 7:106. doi: 10.3390/brainsci7080106 
Neuner, I., Kupriyanova, Y., Stöcker, T., Huang, R., Posnansky, O., Schneider, F., et al. (2010). White-matter abnormalities in Tourette syndrome extend beyond motor pathways. Neuroimage 51, 1184-1193. doi: 10.1016/j.neuroimage.2010.02.049

Paek, S.-H., Park, H., Runco, M. A., and Choe, H.-S. (2016). The contribution of ideational behavior to creative extracurricular activities. Creat. Res. J. 28, 144-148. doi: 10.1080/10400419.2016.1162547

Peterson, B. S., Staib, L., and Scahill, L. (2001). Regional brains and ventricular volumes in Tourette Syndrome. Arch. Gen. Psychiatry 58, 427-440. doi: 10.1001/archpsyc.58.5.427

Porta, M., Sironi, V. A., and Dell'Osso, B. (2017). Smorfie, manie e tic. Da cattive abitudini a fenomeni psicopatologici. Rome: Carocci [Grimaces, manias and tics. From bad habits to psychopathological phenomena].

Robertson, M. M. (2011). Gilles de la Tourette syndrome: the complexities of phenotype and treatment. Br. J. Hospital Med. 72, 100-107. doi: 10.12968/hmed.2011.72.2.100

Runco, M. A., and Charles, R. E. (1993). Judgments of originality and appropriateness as predictors of creativity. Pers. Individ. Dif. 15, 537-546. doi: 10.1016/0191-8869(93)90337-3

Sacks, O. (1992). Tourette's syndrome and creativity. Br. Med. J. 305, 1515-1516. doi: 10.1136/bmj.305.6868.1515

Shamay-Tsoory, S. G., Adler, N., Aharon-Peretz, J., Perry, D., and Mayseless, N. (2011). The origins of originality: the neural bases of creative thinking and originality. Neuropsychologia 49, 178-185. doi: 10.1016/j.neuropsychologia.2010.11.020

Singer, H. S., and Walkup, J. T. (1991). Tourette syndrome and other tic disorders: diagnosis, pathophysiology and treatment. Medicine 70,15-32. doi: 10.1097/00005792-199101000-00002

Szejko, N., Janik, P., and Pasierski, T. (2019). Gilles de la Tourette syndrome: a common disease among uncommonly talented individuals? Psychiatria $i$ Psychol. Kliniczna 19, 77-84. doi: 10.15557/PiPK.201 9.0010
Thenganatt, M. A., and Jankovic, J. (2016). Recent advances in understanding and managing Tourette Syndrome. F1000Research 5:F1000 Faculty Rev-152. doi: 10.12688/f1000research.7424.1

Torrance, E. P. (1998). Torrance Tests of Creative Thinking: Norms-Technical manual. Bensenville, IL: Scholastic Testing Service.

Volle, E., Levy, R., and Burgess, P. W. (2013). “A new era for lesion-behavior mapping of prefrontal functions", in Principles of Frontal Lobe Function, ed. D. T. Stussand, and R. T. Knight (New York, NY: Oxford University Press), 500-523. doi: 10.1093/med/9780199837755.003.0036

Wei, M.-H. (2011). Social adjustment, academic performance, and creativity of Taiwanese children with Tourette's syndrome. Psychol. Rep. 108, 791-798. doi: 10.2466/04.07.10.PR0.108.3.791-798

Zanaboni Dina, C., and Porta, M. (2019). Understanding Tourette syndrome. A guide to symptoms, management and treatment. London: Routledge.

Zanaboni Dina, C., Porta, M., Saleh, C., and Servello, D. (2017). Creativity assessment in subjects with Tourette Syndrome vs. patients with Parkinson's Disease: a preliminary study. Brain Sci. 7:80. doi: 10.3390/brainsci7070080

Zanaboni Dina, C., Rago, S., Cancer, A., and Antonietti, A. (2020). A music-danceimaging training in young adults with Tourette syndrome. Life Span Disability 23, 187-209.

Conflict of Interest: The authors declare that the research was conducted in the absence of any commercial or financial relationships that could be construed as a potential conflict of interest.

Copyright (c) 2021 Colautti, Magenes, Rago, Zanaboni Dina, Cancer and Antonietti. This is an open-access article distributed under the terms of the Creative Commons Attribution License (CC BY). The use, distribution or reproduction in other forums is permitted, provided the original author(s) and the copyright owner(s) are credited and that the original publication in this journal is cited, in accordance with accepted academic practice. No use, distribution or reproduction is permitted which does not comply with these terms. 